\title{
Systemic lupus erythematosus: strategies to improve pregnancy outcomes
}

\author{
This article was published in the following Dove Press journal: \\ International Journal of Women's Health \\ 8 July 2016 \\ Number of times this article has been viewed
}

\section{Yuriko Yamamoto \\ Shigeru Aoki}

Perinatal Center for Maternity and Neonate, Yokohama City University Medical Center, Yokohama, Kanagawa Prefecture, Japan
Correspondence: Shigeru Aoki Perinatal Center for Maternity and Neonate, Yokohama City University Medical Center, 4-57 Urafunecho, Minami-ku, Yokohama, Kanagawa Prefecture 232-0024, Japan

Tel +8I $4526 \mid 5656$

Fax +8I 452535784

Email smyyaoki@yahoo.co.jp
Abstract: Systemic lupus erythematosus (SLE) is a chronic autoimmune inflammatory disease with a high prevalence in females of childbearing age. Thus, reproduction in SLE patients is a major concern for clinicians. In the past, SLE patients were advised to defer pregnancy because of poor pregnancy outcomes and fear of SLE flares during pregnancy. Investigations to date show that maternal and fetal risks are higher in females with SLE than in the general population. However, with appropriate management of the disease, sufferers may have a relatively uncomplicated pregnancy course. Factors such as appropriate preconception counseling and medication adjustment, strict disease control prior to pregnancy, intensive surveillance during and after pregnancy by both the obstetrician and rheumatologist, and appropriate interventions when necessary play a key role. This review describes the strategies to improve pregnancy outcomes in SLE patients at different time points in the reproduction cycle (preconception, during pregnancy, and postpartum period) and also details the neonatal concerns.

Keywords: systemic lupus erythematosus, pregnancy outcomes, lupus flare

\section{Introduction}

Systemic lupus erythematosus (SLE) is a chronic autoimmune inflammatory disease that can affect any organ of the body. The prevalence rate of SLE is 20-70 cases per 100,000 people, and it varies between ethnic groups. ${ }^{1}$ In the US, females of African and Asian descent are two to three times more likely to be affected than those of European descent. ${ }^{2}$ SLE affects females nine times more than males and occurs most frequently between the age of 20 years and 39 years. ${ }^{2}$ This high predisposition of females of childbearing age makes reproduction a major concern for clinicians involved in the care of these patients. In the past, SLE patients were advised to defer pregnancy because of poor pregnancy outcomes and fear of flares during pregnancy. Investigations till date show that the maternal and fetal risks are higher for females with SLE than for the general population. However, the outcomes for SLE patients in general have now improved, and it has also been shown that with appropriate management of the disease, many SLE patients can have a relatively uncomplicated pregnancy course. This review describes the strategies to improve pregnancy outcomes for SLE patients at different time points in the reproduction cycle (preconception, during pregnancy, and postpartum period) and also details the neonatal concerns.

\section{Preconception}

Although SLE patients can theoretically develop ovarian failure due to autoimmune ovarian injury, altered hypothalamic-pituitary-ovarian axis, and diminished ovarian reserve ${ }^{3}$ current evidence suggests that they are as fertile as the general population. ${ }^{4}$ 
The exception to this is when cytotoxic immunosuppressive agents are used for SLE treatment prior to conception. Cyclophosphamide is most toxic to ovarian function and can lead to permanent ovarian failure depending on the patient's age, dose, and duration. ${ }^{5}$ It is known that initiation of treatment at older age and cumulative dose are risk factors for irreversible damage of ovarian function. ${ }^{6,7}$ Anti-Müllerian hormone, secreted from growing ovarian follicles, is considered to be a reliable marker of ovarian reserve, and there are attempts to use this indicator to aid treatment for patients who wish to conceive. ${ }^{4}$ Fertility preservation options should be discussed with patients prior to treatment. If the patient has a history of pregnancy, obstetric outcomes should be carefully reviewed, including history of fetal growth restriction (FGR), pregnancy-induced hypertension and preeclampsia, miscarriage, preterm birth, and intrauterine fetal death.

Based on expert opinion, lupus patients with established organ damage may be advised to avoid pregnancy, including patients with severe pulmonary hypertension (estimated systolic pulmonary artery pressure $>50 \mathrm{mmHg}$ ), advanced renal insufficiency (creatinine level $>2.8 \mathrm{mg} / \mathrm{dL}$ ), severe restrictive lung disease (forced vital capacity $<1 \mathrm{~L}$ ), heart failure, a history of severe preeclampsia or a severe lupus flare within the past 6 months, active lupus nephritis, or stroke. ${ }^{8}$

In order to improve pregnancy outcomes in SLE patients, pregnancy should be well planned. Disease activity at the time of conception is an indicator of maternal outcomes, and high activity leads to poor outcomes. Based on a multicenter analysis of 56 pregnancies of patients diagnosed with SLE before pregnancy, many agree that prognosis for both mother and child is best when SLE activity is in remission for at least 6 months before conception., ${ }^{9,10}$ Compared with patients with clinically active SLE before conception, those in remission for at least 6 months before conception had a higher live birth rate (64\% versus $88 \%$ ), full-term delivery (64\% versus 56\%), and lower rate of exacerbation of SLE during pregnancy or postpartum (32\% versus $28 \%) .{ }^{11}$ In a retrospective analysis of 183 pregnancies in Korean females with SLE, based on a receiver operating characteristic curve for prediction of adverse pregnancy outcomes, Ko et al stated that a stable period of at least 4 months is essential in reducing pregnancy loss, premature birth, pregnancy-induced hypertension, and FGR. ${ }^{12}$ An overview of the risk assessment in the SLE patients is summarized in Table 1.

\section{Contraception}

Contraception options for SLE patients depends on current disease activity, presence of antiphospholipid (aPL)
Table I Preconception risk assessment for SLE patients

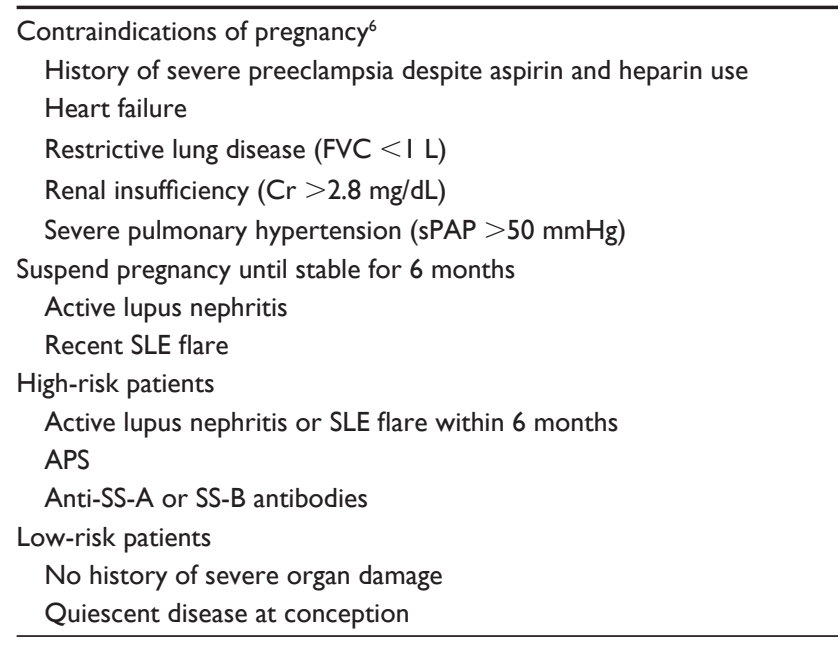

Abbreviations: SLE, systemic lupus erythematosus; FVC, forced vital capacity; $\mathrm{Cr}$, creatinine; sPAP, systolic pulmonary artery pressure; APS, antiphospholipid syndrome.

antibodies, age, reproductive history, and other factors such as patient's preference and cultural values. Intrauterine device is a safe option, and no increased risk is reported for infection with combined use of immunosuppressive medication. ${ }^{12}$ For stable patients with low disease activity and negative aPLs, estrogen-progestin contraception seems to be a safe option. ${ }^{13}$ However, patients on medications that might interact with estrogen-containing pills such as mycophenolate, corticosteroids, cyclosporine, and warfarin need to be evaluated for the risks and benefits of its use. For patients with a higher risk of thrombosis, progestin-only contraception may be an option. However, information on the risk of thromboembolism in SLE patients on progestinonly contraception is still not sufficient, and guidelines on its use are still controversial. ${ }^{14}$ Because of its low effectiveness, barrier methods such as condoms and diaphragms may be necessary as a second-line method when other options are contraindicated. Emergency contraception is indicated regardless of disease activity or aPL status, and patients should be well informed of the option. ${ }^{15}$

\section{Medication}

Discontinuation of medication before conception by the patient for fear of fetotoxicity is a frequently encountered problem in practice. Patients should be well informed that discontinuation of medication may activate SLE and lead to pregnancy complications.

When planning pregnancy, medication of the patient must be reviewed and adjusted to minimize its effect on the fetus while maintaining the current stable condition of the mother. 
Nonsteroidal anti-inflammatory drug is commonly prescribed to SLE patients and is generally safe during pregnancy, except in the third trimester, which may cause premature closure of ductus arteriosus. Low-dose aspirin, which is often used for the prevention of preeclampsia, is also considered safe. Antihypertensive medications such as nifedipine, methyldopa, and hydralazine are widely used during pregnancy. ${ }^{16}$ On the other hand, angiotensin-converting enzyme inhibitors and angiotensin II receptor blockers are contraindicated throughout pregnancy because of their association with congenital anomalies and pregnancy complications. ${ }^{17}$ Hydroxychloroquine use is encouraged throughout pregnancy because of its safety profile and possible preventive effect against neonatal congenital heart block (described in the "Neonatal concerns" section). The effects of glucocorticoids include a possible increase in the incidence of oral cleft in the fetus, FGR, and premature rupture of membranes, although reports are conflicting. ${ }^{18}$

Among the immunosuppressive agents, cyclophosphamide, methotrexate, and mycophenolate are contraindicated during pregnancy because of their association with congenital anomalies. ${ }^{19-21}$ Azathioprine is considered relatively safer than other immunosuppressive drugs, and many reports encourage transition for patients who wish to conceive. ${ }^{22}$ However, recently, concerns have been raised for late developmental delays in children who were exposed to azathioprine in utero. ${ }^{23}$ Calcineurin inhibitors such as tacrolimus and cyclosporine also seem to be acceptable options. ${ }^{24,25}$ The biological agents such as anti-TNF agents and rituximab administered by pregnant females with rheumatoid arthritis and inflammatory bowel disease do not seem to place the mother and fetus at risk at the time of conception and during the first trimester. ${ }^{26}$ However, their use in the third trimester must be cautioned, as these agents readily cross the placenta and fatal infection has been reported after live vaccination in an exposed infant. ${ }^{27}$

\section{During pregnancy}

Whether SLE activity is influenced by pregnancy has been a controversial subject for decades. It is generally considered that SLE flares are likely during pregnancy. However, some argue that SLE activity is worsened, ${ }^{28,29}$ while others report that no change in disease activity is observed. ${ }^{30}$ The mixed results are understandable, as the studies were mostly retrospective in design and patient history such as disease activity at the time of conception, previous history of disease, and medication profile were diverse. In addition, different definitions were given for disease flare and, as described below, lupus flare during pregnancy is often difficult to distinguish from preeclampsia. Recently, attention is less on whether flare is likely or not and is more on which specific population of patients needs special attention for exacerbation of SLE. Some argue that in patients with stable condition at the time of conception, disease activity is generally not worsened, and even if so, the flare is usually mild and seldom requires a change in the treatment..$^{9,11,31}$ A history of lupus nephritis and active disease at the time of conception are indicators of poor maternal outcomes. ${ }^{32,33}$

On the other hand, the effects of the disease on pregnancy outcomes are clear. The incidence of complications, including preeclampsia, prematurity, FGR, and fetal loss, is higher in SLE patients than that in the general population. Preeclampsia is reported to occur in $7.5 \%-22 \%{ }^{34-38}$ of pregnant SLE patients, which is higher than $\sim 3 \%$ in the general population. ${ }^{39}$ It is not clear why these adverse outcomes are increased in SLE patients; lupus nephritis and aPL antibodies have been identified as risk factors. The direct effect on placental trophoblast and complement activation, as well as procoagulant effect of aPL, seems to play a role in the pathogenesis. ${ }^{40,41}$ Premature delivery, either indicated or spontaneous, is observed in $12.1 \%-54 \%$ of patients. ${ }^{9,11,34-38,42-44}$ The incidence rate of fetal loss was reported as 3\%-36\%, which varies among studies. $33,35,38,44,45$ The incidence rate of these adverse outcomes is reported to substantially increase for females with a history of nephritis, positive aPL, and active disease at conception. ${ }^{46,47}$ Lupus nephritis and antiphospholipid syndrome (APS) are discussed separately in the following sections.

Pregnant females with SLE should be closely monitored by both an experienced obstetrician and a rheumatologist. Neonatal care should be readily available considering the high rate of premature birth. Although no consensus has been reached on management strategies, recommendations have been made to achieve early detection of change in SLE activity, fetal compromise, and maternal complications. ${ }^{48,49}$ The key points in management of pregnant SLE patients are described in Table 2.

\section{Lupus nephritis}

Patients with a previous history of lupus nephritis or active lupus nephritis during pregnancy require careful monitoring during pregnancy, as they are associated with higher rates of maternal and fetal complications. In a cohort study of 166 pregnancies, first-trimester proteinuria, indicative of lupus nephritis, resulted in a 2.6-fold increase in pregnancy loss. ${ }^{46}$ Renal involvement, defined as proteinuria in the absence of 
Table 2 Key points in managing the pregnant SLE patients

\begin{tabular}{|c|c|c|c|}
\hline & Observant & Timing & Monitoring details \\
\hline \multirow[t]{8}{*}{$\begin{array}{l}\text { Maternal } \\
\text { monitoring }\end{array}$} & Obstetrician & First visit & $\begin{array}{l}\text { History taking, physical examination, urine analysis (if dipstick } \\
\text { is positive for protein, measure protein-creatinine ratio) }\end{array}$ \\
\hline & & Repeated monthly until 20 weeks & \\
\hline & & Every 2 weeks until 24 weeks & \\
\hline & & Every week until delivery & \\
\hline & Rheumatologist & First visit & $\begin{array}{l}\text { History taking, physical examination, complement, anti } \\
\text { ds-DNA antibody, SS-A and SS-B antibodies, cardiolipin } \\
\text { antibodies, lupus anticoagulant }\end{array}$ \\
\hline & & Repeat every month until postpartum & History taking, physical examination, complement \\
\hline & Both & First visit & CBC, chemistry (including uric acid, liver enzymes, creatinine) \\
\hline & & Repeat every month until postpartum & Protein-creatinine ratio \\
\hline \multirow[t]{5}{*}{ Fetal monitoring } & Obstetrician & Starting at 16 weeks & Echocardiogram \\
\hline & & Starting at 24 weeks & BPP, fetal growth, umbilical artery Doppler velocimetry \\
\hline & & Repeated every week until delivery & \\
\hline & Neonatologist & When signs of fetal compromise detected & Consultation for appropriate timing/mode of delivery \\
\hline & Cardiologist & When signs of $\mathrm{CHB}$ or heart failure detected & Consultation for therapy and appropriate timing/mode of delivery \\
\hline
\end{tabular}

Abbreviations: SLE, systemic lupus erythematosus; CBC, complete blood count; BPP, biophysical profile; CHB, congenital heart block; dsDNA, double stranded DNA.

preeclampsia or dysmorphic hematuria and cellular casts in urine, was reported as a prognostic factor of FGR and/or preeclampsia in a retrospective study of 65 pregnancies. ${ }^{38}$ As discussed earlier, in order to improve pregnancy outcome in this patient population, females with active lupus nephritis should be advised to postpone pregnancy until the disease is in remission for at least 6 months. Lupus nephritis in pregnancy should be dealt with caution, because it can possibly lead to irreversible renal injury. ${ }^{33}$ In addition, it is often difficult to differentiate renal flare and preeclampsia, which can cause dilemma in the choice of treatment. Details on treatment are described as follows.

\section{Treatment of SLE flare during pregnancy}

The treatment of SLE flare during pregnancy is the same as that in nonpregnancy. The choice of medication and dose depends on the severity and the degree of organ involvement. However, special consideration is necessary for the possible harm it may do to the fetus. The risks and benefits of initiating treatment should be evaluated carefully. When indicated, the treatment should not be withheld due to pregnancy, as it may lead to serious morbidity and mortality. ${ }^{32}$

Diagnosis of SLE exacerbation during pregnancy is challenging, as many physiological changes in normal pregnancy and obstetric complications may mimic SLE symptoms. For instance, mild thrombocytopenia, anemia, arthralgia, edema, mild dyspnea, and effusion of knees, which are all frequent observations during pregnancy, can be confused with early signs of flare. ${ }^{48,50}$ Complement levels are also known to be slightly elevated during pregnancy. ${ }^{51}$ The $\mathrm{C} 3$ and $\mathrm{C} 4$ levels must be evaluated in caution, because even a sign of slight decrease in the normal range might indicate lupus flare. ${ }^{50}$

In particular, renal flare and preeclampsia are difficult to differentiate, which share clinical features including hypertension, proteinuria, and thrombocytopenia. Moreover, the two conditions may coexist, further complicating management of the condition. ${ }^{48,52-54}$ When preeclampsia is suspected as the culprit of the medical condition and termination of pregnancy is indicated, one should always keep in mind the possibility of coexisting lupus nephritis. When lupus nephritis is involved in the pathogenesis, the patient's condition might worsen. ${ }^{52}$ Some key points to differentiate preeclampsia and renal flare are listed in Table 3. It is

Table 3 Key points to differentiate preeclampsia from lupus nephritis

\begin{tabular}{|c|c|c|}
\hline & Preeclampsia & Lupus nephritis \\
\hline Onset & After 20 weeks & $\begin{array}{l}\text { Possible onset before } \\
20 \text { weeks }\end{array}$ \\
\hline Hypertension & Present & May be present or absent \\
\hline $\begin{array}{l}\text { Urinary } \\
\text { sediment }\end{array}$ & Negative & Positive \\
\hline Uric acid & $>4.9 \mathrm{mg} / \mathrm{dL}$ & $<4.9 \mathrm{mg} / \mathrm{dL}^{90}$ \\
\hline Complement & No change & $\begin{array}{l}\text { Decrease from baseline } \\
\text { during pregnancy (could be } \\
\text { within the normal range) }\end{array}$ \\
\hline Anti-dsDNA & No change & Increased \\
\hline $\begin{array}{l}\text { Other signs } \\
\text { of SLE activity }\end{array}$ & Absent & Present \\
\hline $\begin{array}{l}\text { Urinary } \\
\text { calcium }\end{array}$ & $<195 \mathrm{mg} / 24$ hours & $>195$ mg/24 hours ${ }^{91}$ \\
\hline
\end{tabular}
erythematosus. 
essential that obstetricians discuss each case individually with a rheumatologist.

\section{Antiphospholipid syndrome}

APS is an autoimmune disorder characterized by the occurrence of venous and arterial thromboses, which may or may not coexist with other autoimmune diseases such as SLE. In a study of 1,000 patients with a diagnosis of APS, $36.2 \%$ were found to have SLE. ${ }^{55}$ Its diagnosis consists of the presence of both specific autoantibodies and clinical manifestations. ${ }^{56}$ One of the major clinical manifestations of APS is adverse obstetric outcomes such as 1) three or more consecutive spontaneous abortions before 10 weeks of gestation, 2) one or more unexplained fetal loss beyond 10 weeks of gestation, or 3 ) one or more premature births of a morphologically normal neonate before 34 weeks of gestation due to eclampsia or preeclampsia. ${ }^{56}$ When APS is diagnosed together with SLE or other autoimmune diseases, the risk of adverse pregnancy outcomes is higher. ${ }^{57}$ The treatment for APS includes prevention of adverse pregnancy outcomes by aspirin or aspirin in combination with heparin started empirically to prevent thrombosis. ${ }^{58}$ However, studies from animal models suggest that inflammation also plays a key role in the pathogenesis of APS, ${ }^{59,60}$ and the anti-inflammatory aspect of heparin might also be responsible for the effect on outcomes. ${ }^{49,51}$ Management of APS during pregnancy depends on whether the patient has a history of thrombosis. For those with a history of thrombotic event, most experts recommend heparin use until 6 weeks postpartum. Although the effectiveness is not proven, it is common to use aspirin in combination with heparin. The optimal treatment for those without a history of thrombosis is not well studied. ${ }^{61}$ Randomized controlled trials have shown that the combination of aspirin and heparin is superior to aspirin alone in preventing pregnancy loss and that pregnancies that ended in live births had favorable outcomes $^{62,63}$ on the other hand there is a study that shows aspirin alone is equally effective in pregnancy loss. ${ }^{64}$ These trials are of small scale, vary in therapeutic protocols, and, most importantly, exclude SLE patients. Some retrospective studies on the effectiveness of pharmacological treatment for APS patients include SLE patients, but their therapeutic regimens and diagnosis of APS are not consistent. ${ }^{64-67}$ One systematic review based on two small trials concluded that a combination of heparin and aspirin reduced pregnancy loss by $54 \%$ in patients with a history of at least one pregnancy loss and positive aPL. ${ }^{68}$ Well-designed trials are necessary to find the appropriate treatment for lupus patients with APS. Currently, expert opinion favors the use of aspirin during pregnancy and also anticoagulation with heparin postpartum to reduce the risks of thrombosis in APS patients. ${ }^{69-71}$

\section{Postpartum period}

SLE flares can occur after termination of pregnancy, especially in patients with active disease at conception and during pregnancy. ${ }^{72}$ Of note, for those who have terminated pregnancy due to SLE flare or with coexisting preeclampsia, intensive monitoring for severe maternal postpregnancy exacerbations is needed. ${ }^{52,73}$ The treatment for postpartum females with active SLE is similar to that for nonpregnant females. Many medications for aggressive therapy are not compatible with breastfeeding. ${ }^{18}$ Breastfeeding females must be informed of the risks and benefits of continuing lactation during treatment.

\section{Neonatal concerns}

Neonates born to mothers with SLE need to be monitored for neonatal lupus (NL). NL is believed to be caused by transplacental transfer of the autoantibodies anti-Ro/SSA and anti-RA/SSB to the newborn. The incidence rate of cardiac NL was reported as $1 \%-2 \%$ in mothers who are antibody positive and can increase to as high as $18 \%$ in mothers who had previously given birth to an affected child. ${ }^{74,75}$ The major clinical manifestations of NL are rash and heart block. Cutaneous involvement is typically observed as multiple erythematous macules or plaques around the head and neck at birth to 20 weeks of age. The mean age of detection of the rash was 6 weeks. ${ }^{76}$ It is usually self-limiting, disappearing as the circulating antibodies are removed, but some might have residual telangiectasia and hyperpigmentation in the affected area. ${ }^{76}$ Cardiac manifestation of NL is more serious, with a reported mortality as high as 16\%-17.5\% and pacemaker implantation is required for $\sim 70 \%$ of patients by the age of 10 years. ${ }^{77,78}$

In order to improve outcomes in fetus/neonates diagnosed with heart block, close monitoring is necessary during pregnancy and after delivery, as a first- or second-degree heart block can potentially progress to a third-degree heart block, necessitating pacemaker implantation. Heart block is often diagnosed between 18 weeks and 24 weeks of gestation by using echocardiography, and a diagnosis of onset is rare after 30 weeks of pregnancy. ${ }^{74,79}$ Thus, intensive fetal echocardiography during this period is essential for early diagnosis. In addition, prenatal fluorinated steroids can reverse a second-degree heart block, ${ }^{79-81}$ although its efficacy is still controversial. ${ }^{77}$ Intravenous immunoglobulin and plasmapheresis have also been considered as candidate 
agents to reverse the progression of heart block, but have not been proven as effective. ${ }^{82,83}$

Hydroxychloroquine, originally an antimalarial medication, has been widely prescribed to patients with autoimmune disease, especially SLE patients. ${ }^{84}$ It is believed to prevent tissue injury by interfering with Toll-like receptor activity. ${ }^{85}$ In a recent retrospective study, this medication has been associated with a reduction in the incidence of cardiac NL in mothers who had previously given birth to an affected child. ${ }^{86} \mathrm{~A}$ few other studies have indicated the possible therapeutic effect of hydroxychloroquine for congenital heart block. ${ }^{87-89}$

\section{Summary}

With better treatment options and extensive clinical and molecular research, many SLE patients can have favorable pregnancy outcomes with careful management. Factors such as appropriate preconception counseling and medication adjustment, strict disease control prior to pregnancy, intensive surveillance during and after pregnancy by both the obstetrician and rheumatologist, and appropriate interventions when necessary play a key role.

\section{Disclosure}

The authors report no conflicts of interest in this work.

\section{References}

1. Pons-Estel GJ, Alarcón GS, Scofield L, Reinlib L, Cooper GS. Understanding the epidemiology and progression of systemic lupus erythematosus. Semin Arthritis Rheum. 2010;39(4):257-268.

2. McCarty DJ, Manzi S, Medsger TA Jr, Ramsey-Goldman R, LaPorte RE, Kwoh CK. Incidence of systemic lupus erythematosus. Race and gender differences. Arthritis Rheum. 1995;38(9):1260-1270.

3. Oktem O, Guzel Y, Aksoy S, Aydin E, Urman B. Ovarian function and reproductive outcomes of female patients with systemic lupus erythematosus and the strategies to preserve their fertility. Obstet Gynecol Surv. 2015;70(3):196-210.

4. Gasparin AA, Souza L, Siebert M, et al. Assessment of anti-Mullerian hormone levels in premenopausal patients with systemic lupus erythematosus. Lupus. 2016;25(3):227-232.

5. Mok CC, Lau CS, Wong RW. Risk factors for ovarian failure in patients with systemic lupus erythematosus receiving cyclophosphamide therapy. Arthritis Rheum. 1998;41(5):831-837.

6. Wang CL, Wang F, Bosco JJ. Ovarian failure in oral cyclophosphamide treatment for systemic lupus erythematosus. Lupus. 1995;4(1): $11-14$.

7. Appenzeller S, Blatyta PF, Costallat LT. Ovarian failure in SLE patients using pulse cyclophosphamide: comparison of different regimes. Rheumatol Int. 2008;28(6):567-571.

8. Ruiz-Irastorza G, Khamashta MA. Lupus and pregnancy: ten questions and some answers. Lupus. 2008;17(5):416-420.

9. Mintz G, Niz J, Gutierrez G, Garcia-Alonso A, Karchmer S. Prospective study of pregnancy in systemic lupus erythematosus. Results of a multidisciplinary approach. J Rheumatol. 1986;13(4):732-739.

10. Ruiz-Irastorza G, Khamashta MA. Lupus and pregnancy: integrating clues from the bench and bedside. Eur J Clin Invest. 2011;41(6): 672-678.
11. Hayslett JP, Lynn RI. Effect of pregnancy in patients with lupus nephropathy. Kidney Int. 1980;18(2):207-220.

12. Ko HS, Ahn HY, Jang DG, et al. Pregnancy outcomes and appropriate timing of pregnancy in 183 pregnancies in Korean patients with SLE. Int J Med Sci. 2011;8(7):577-583.

13. Stringer EM, Kaseba C, Levy J, et al. A randomized trial of the intrauterine contraceptive device vs hormonal contraception in women who are infected with the human immunodeficiency virus. Am J Obstet Gynecol. 2007;197(2):144.e1-144.e8.

14. Sanchez-Guerrero J, Uribe AG, Jimenez-Santana L, et al. A trial of contraceptive methods in women with systemic lupus erythematosus. N Engl J Med. 2005;353(24):2539-2549.

15. Mantha S, Karp R, Raghavan V, Terrin N, Bauer KA, Zwicker JI. Assessing the risk of venous thromboembolic events in women taking progestin-only contraception: a meta-analysis. BMJ. 2012;345:e4944.

16. Practice bulletin no. 152: emergency contraception. Obstet Gynecol. 2015;126(3):e1-e11.

17. Henderson JT, Whitlock EP, O'Connor E, Senger CA, Thompson JH, Rowland MG. Low-dose aspirin for the prevention of morbidity and mortality from preeclampsia: a systematic evidence review for the U.S. Preventive Services Task Force. Ann Intern Med. 2014;160(10): 695-703.

18. Shotan A, Widerhorn J, Hurst A, Elkayam U. Risks of angiotensinconverting enzyme inhibition during pregnancy: experimental and clinical evidence, potential mechanisms, and recommendations for use. Am J Med. 1994;96(5):451-456.

19. Ostensen M, Khamashita M, Lockshin M, et al. Anti-inflammatory and immunosuppressive drugs and reproduction. Arthritis Res Ther. 2006;8(3):209-227.

20. Kirshon B, Wasserstrum N, Willis R, Herman GE, McCabe ER. Teratogenic effect of first-trimester cyclophosphamide therapy. Obstet Gynecol. 1988;72(3):462-464.

21. Buckley LM, Bullaboy CA, Leichtman L, Marquez M. Multiple congenital anomalies associated with weekly low-dose methotrexate treatment of the mother. Arthritis Rheum. 1997;40(5):971-973.

22. Hoeltzenbein M, Elephant E, Vial T, et al. Teratogenicity of mycophenolate confirmed in a prospective study of the European Network of Teratology Information Services. Am J Med Genet. 2012;158A(3): 588-596.

23. Fischer-Betz R, Specker C, Brinks R, Aringer M, Schneider M. Low risk of renal flares and negative outcomes in women with lupus nephritis conceiving after switching from mycophenolate mofetil to azathioprine. Rheumatology. 2013;52(6):1070-1076.

24. Marder W, Ganser MA, Romero V, et al. In utero azathioprine exposure and increased utilization of special educational services in children born to mothers with systemic lupus erythematosus. Arthritis Care Res. 2013;65(5):759-766.

25. Kim H, Jeong JC, Yang J, et al. The optimal therapy of calcineurin inhibitors for pregnancy in kidney transplantation. Clin Transplant. 2015;29(2):142-148.

26. Webster P, Wardle A, Bramham K, Webster L, Nelson-Piercy C, Lightstone $\mathrm{L}$. Tacrolimus is an effective treatment for lupus nephritis in pregnancy. Lupus. 2014;23(11):1192-1196.

27. Hyrich KL, Verstappen SMM. Biologic therapies and pregnancy: the story so far. Rheumatology. 2014;53(8):1377-1385.

28. Cheent K, Nolan J, Shariq S, Kiho L, Pal A, Arnold J. Case report: Fatal case of disseminated BCG infection in an infant born to a mother taking infliximab for Crohn's disease. J Crohns Colitis. 2010;4(5): 603-605.

29. Petri M, Howard D, Repke J. Frequency of lupus flare in pregnancy: the Hopkins Lupus Pregnancy Center experience. Arthritis Rheum. 1991;34(12):1538-1545.

30. Ruiz-Irastorza G, Lima F, Alves J, et al. Increased rate of lupus flare during pregnancy and the puerperium: a prospective study of 78 pregnancies. Br J Rheumatol. 1996;35(2):133-138.

31. Lockshin MD, Reinitz E, Druzin ML, Murrman M, Estes D. Casecontrol prospective study demonstrating absence of lupus exacerbation during or after pregnancy. Am J Med. 1984;77(5):893-898. 
32. Georgiou PE, Politi EN, Katsimbri P, Sakka V, Drosos AA. Outcome of lupus pregnancy: a controlled study. Rheumatology. 2000; 39(9):1014-1019.

33. Ritchie J, Smyth A, Tower C, Helbert M, Venning M, Garovic VD. Maternal deaths in women with lupus nephritis: a review of published evidence. Lupus. 2012;21(5):534-541.

34. Moroni G, Ponticelli C. Pregnancy after lupus nephritis. Lupus. 2005; 14(1):89-94.

35. Carmona F, Font J, Cervera R, Munoz F, Cararach V, Balasch J. Obstetrical outcome of pregnancy in patients with systemic lupus erythematosus. A study of 60 cases. Eur J Obstet Gynecol. 1999;83(2):137-142.

36. Shand A, Algert CS, March L, Roberts CL. Second pregnancy outcomes for women with systemic lupus erythematosus. Ann Rheum Dis. 2013;72(4):547-551.

37. Wong CH, Chen TL, Lee CS, Lin CJ, Chen CP. Outcome of pregnancy in patients with systemic lupus erythematosus. Taiwan J Obstet Gynecol. 2006;45(2):120-123.

38. Barnabe C, Faris PD, Quan H. Canadian pregnancy outcomes in rheumatoid arthritis and systemic lupus erythematosus. Int J Rheumatol. 2011;2011:345727.

39. Madazli R, Yuksel MA, Oncul M, Imamoglu M, Yilmaz H. Obstetric outcomes and prognostic factors of lupus pregnancies. Arch Gynecol Obstet. 2013;289(1):49-53.

40. Hutcheon JA, Lisonkova S, Joseph KS. Epidemiology of pre-eclampsia and the other hypertensive disorders of pregnancy. Best Pract Res Clin Obstet Gynaecol. 2011;25(4):391-403.

41. Holers VM, Girardi G, Mo L, et al. Complement C3 activation is required for antiphospholipid antibody-induced fetal loss. J Exp Med. 2002;195(2):211-220.

42. Tong M, Viall CA, Chamley LW. Antiphospholipid antibodies and the placenta: a systematic review of their in vitro effects and modulation by treatment. Hum Reprod Update. 2015;21(1):97-118.

43. Chakravarty EF, Colon I, Langen ES, et al. Factors that predict prematurity and preeclampsia in pregnancies that are complicated by systemic lupus erythematosus. Am J Obstet Gynecol. 2005;192(6):1897-1904.

44. Petri M, Allbritton J. Fetal outcome of lupus pregnancy: a retrospective case-control study of the Hopkins Lupus Cohort. J Rheumatol. 1993; 48(11):717-719

45. Cortes-Hernandez J, Ordi-Ros J, Paredes F, Casellas M, Castillo F, Vilardell-Tarres M. Clinical predictors of fetal and maternal outcome in systemic lupus erythematosus: a prospective study of 103 pregnancies. Rheumatol. 2002;41(6):643-650.

46. Vinet E, Labrecque J, Pineau CA, et al. A population-based assessment of live births in women with systemic lupus erythematosus. Ann Rheum Dis. 2012;71(4):557-559.

47. Clowse MEB, Magder LS, Witter F, Petri M. Early risk factors for pregnancy loss in lupus. Am J Obstet Gynecol. 2006;107(2):293-299.

48. Andreoli L, Fredi M, Nalli C, et al. Pregnancy implications for systemic lupus erythematosus and the antiphospholipid syndrome. J Autoimmun. 2012;38(2-3):J197-J208.

49. Baer AN, Witter FR, Petri M. Lupus and pregnancy. Obstet Gynecol Surv. 2011;66(10):639-653.

50. Petri M. The Hopkins Lupus Pregnancy Center: ten key issues in management. Rheum Dis Clin North Am. 2007;33(2):227-235.

51. Doria A, Tincani A, Lockshin M. Challenges of lupus pregnancies. Rheumatology. 2008;47(supp1 3):iii9-iii12.

52. Abramson SA, Buyon JP. Activation of the complement pathway: comparison of normal pregnancy, preeclampsia, and systemic lupus erythematosus during pregnancy. Am J Reprod Immunol. 1992;28(3-4):183-187.

53. Aoki S, Mochimaru A, Yamamoto Y, Kurasawa K, Takahashi T, Hirahara F. Pregnancy outcomes of women with coexisting systemic lupus erythematosus flare and preeclampsia. Mod Rheumatol. 2015;25(3): $410-414$.

54. Gordon P, Beedham T, Khamashta MA, D'Cruz D. Systemic lupus erythematosus in pregnancy. Obstet Gynaecol. 2004;6(2):80-87.

55. Ruiz-Irastorza G, Khamashta MA. Evaluation of systemic lupus erythematosus activity during pregnancy. Lupus. 2004;13(9): 679-682.
56. Cervera R, Piette JC, Font J, et al. Antiphospholipid syndrome: clinical and immunologic manifestations and patterns of disease expression in a cohort of 1,000 patients. Arthritis Rheum. 2002;46(4):1019-1027.

57. Miyakis S, Lockshin MD, Atsumi T, et al. International consensus statement on an update of the classification criteria for definite antiphospholipid syndrome (APS). J Thromb Haemost. 2006;4(2):295-306.

58. Ruffatti A, Tonello M, Visentin MS, et al. Risk factors for pregnancy failure in patients with anti-phospholipid syndrome treated with conventional therapies: a multicenter, case-control study. Rheumatology. 2011;50(9):1684-1689.

59. Salmon JE, Girardi G, Lockshin MD. The antiphospholipid syndrome as a disorder initiated by inflammation: implications for the therapy of pregnant patients. Nat Clin Prac Rheum. 2007;3(3):140-147.

60. Giannakopoulos B, Krilis SA. The pathogenesis of the antiphospholipid syndrome. N Eng J Med. 2013;368(11):1033-1044.

61. Practice bulletin no. 132: antiphospholipid syndrome. Obstet Gynecol. 2012;120(6):1514-1521.

62. Rai R, Cohen H, Dave M, Regan L. Randomized controlled trial of aspirin and aspirin plus heparin in pregnant women with recurrent miscarriage associated with phospholipid antibodies (or antiphospholipid antibodies). BMJ. 1997;314:253-257.

63. Kutteh WH. Antiphospholipid antibody-associated recurrent pregnancy loss: treatment with heparin and low-dose aspirin is superior to low-dose aspirin alone. Am J Obstet Gynecol. 1996;174(5):1584-1589.

64. Farquharson RG, Quenby S, Greaves M. Antiphospholipid syndrome in pregnancy: a randomized, controlled trial of treatment. Obstet Gynecol. 2002;100(3):408-413.

65. Lockshin MD, Druzin ML, Qamar T. Prednisone does not prevent recurrent fetal death in women with antiphospholipid antibody. $\mathrm{Am} \mathrm{J}$ Obstet Gynecol. 1989;160(2):439-443.

66. Branch DW, Silver RM, Blackwell JL, Reading JC, Scott JR. Outcome of treated pregnancies in women with antiphospholipid syndrome: an update of the Utah experience. Obstet Gynecol. 1992;80(4):614-620.

67. Lima F, Khamashta MA, Buchanan NM, Kerslake S, Hunt BJ, Hughes GRA. Study of sixty pregnancies in patients with the antiphospholipid syndrome. Clin Exp Rheumatol. 1996;14(2):131-136.

68. Rosove MH, Tabsh K, Wasserstrum N, Howard P, Hahn BH, Kalunian KC. Heparin therapy for pregnant women with lupus anticoagulant of anticardiolipin antibodies. Obstet Gynecol. 1990;75(4):630-634.

69. Empson M, Lassere M, Craig JC, Scott JR. Recurrent pregnancy loss with antiphospholipid antibody: a systematic review of therapeutic trials. Obstet Gynecol. 2002;99(1):135-144.

70. Derksen RHWM, Khamashta MA, Branch DW. Management of the obstetric antiphospholipid syndrome. Arthritis Rheum. 2004;50(4): 1028-1039.

71. Schramm AM, Clowse MEB. Aspirin prevention of preeclampsia in lupus pregnancy. Autoimmun Dis. 2014;2014:920467.

72. Bertsias G, Ioannidis JPA, Boletis J, et al. EULAR recommendations for the management of systemic lupus erythematosus. Report of a task force of the EULAR standing committee for international clinical studies including therapeutics. Ann Rheum Dis. 2008;67(2):195-205.

73. Andrade RM, McGwin G Jr, Alarcon GS, et al. Predictors of postpartum damage accrual in systemic lupus erythematosus: data from LUMINA, a multiethnic US cohort (XXXVIII). Rheumatology. 2006; 45(11):1380-1384.

74. El-sayed YY, Lu EJ, Genovese MC, Lambert RE, Chitkara U, Druzin ML. Central nervous system lupus and pregnancy: 11-year experience at a single center. J Matern Fet Neonat Med. 2002;12(2):99-103.

75. Llanos C, Izmirly PM, Katholi M, et al. Recurrence rates of cardiac manifestations associated with neonatal lupus and maternal/fetal risk factors. Arthritis Rheum. 2009;60(10):3091-3097.

76. Gladman G, Silverman ED, Yuk-Law, et al. Fetal echocardiographic screening of pregnancy of mothers with anti-Ro and/or anti-La antibodies. Am J Perinatol. 2002;19(2):73-80.

77. Neiman AR, Lee LA, Weston WL, Buyon JP. Cutaneous manifestations of neonatal lupus without heart block: characteristics of mothers and children enrolled in a national registry. J Pediatr. 2000;137(5): 674-680. 
78. Eliasson H, Sonesson SE, Sharland G, et al. Isolated atrioventricular block in the fetus: a retrospective, multinational, multicenter study of 175 patients. Circulation. 2011;124(18):1919-1926.

79. Izmirly PM, Saxena A, Kim MY, et al. Maternal and fetal factors associated with mortality and morbidity in a multi-racial/ethnic registry of anti-SSA/Ro-associated cardiac neonatal lupus. Circulation. 2011;124(18):1927-1935.

80. Brucato A. Prevention of congenital heart block in children of SSApositive mothers. Rheumatology. 2008;47(suppl 3):iii35-iii37.

81. Rein AJ, Mevorach D, Perles Z, et al. Early diagnosis and treatment of atrioventricular block in the fetus exposed to maternal anti-SSA/RoSSB/La antibodies: a prospective observational, fetal kinetocardiogrambased study. Circulation. 2009;119(14):1867-1872.

82. Jaeggi ET, Fouron JC, Silverman ED, Ryan G, Smallhorn J, Hornberger LK. Transplacental fetal treatment improves the outcome of prenatally diagnosed complete atrioventricular block. Circulation. 2004; 110(12):1542-1548.

83. Friedman DM, Llanos C, Izmirly PM, et al. Evaluation of fetuses in the preventive IVIG therapy for congenital heat block (PITCH) study. Arthritis Rheum. 2010;62(4):1138-1146.

84. Pisoni CN, Brucato A, Ruffatti A, et al. Failure of intravenous immunoglobulin to prevent congenital heart block: findings of a multicenter, prospective, observational study. Arthritis Rheum. 2010;62(4): 1147-1152.
85. Clowse MEB, Magder L, Witter F, Petri M. Hydroxychloroquine in lupus pregnancy. Arthritis Rheum. 2006;54(11):3640-3647.

86. Sacre K, Criswell LA, McCune JM. Hydroxychloroquine is associated with impaired interferon-alpha and tumor necrosis factor-alpha production by plasmacytoid dendritic cells in systemic lupus erythematosus. Arthritis Res Ther. 2012;14(3):R155.

87. Izmirly PM, Costedoat-Chalumeau N, Pisoni CN, et al. Maternal use of hydroxychloroquine is associated with a reduced risk of recurrent anti-SSA/Ro-antibody-associated cardiac manifestations of neonatal lupus. Circulation. 2012;126(1):76-82.

88. Tunks RD, Clowse MEB, Miller SG, Brancazio LR, Barker PCA. Maternal autoantibody levels in congenital heart block and potential prophylaxis with anti-inflammatory agents. Am J Obstet Gynecol. 2013;208(64):e1-e7.

89. Saxena A, Izmirly PM, Mendez B, Buyon JP, Friedman DM. Prevention and treatment in utero of autoimmune associated congenital heart block. Cardiol Rev. 2014;22(6):263-267.

90. Salahuddin S, Lee Y, Vadnais M, Sachs BP, Karumanchi SA, Lim KH. Diagnostic utility of soluble fms-like tyrosine kinase 1 and soluble endoglin in hypertensive diseases of pregnancy. Am J Obstet Gynecol. 2007;197(28):e1-e6.

91. Sanchez-Ramos L, Jones DC, Cullen MT. Urinary calcium as an early marker for preeclampsia. Obstet Gynecol. 1991;77(5):685-688.
International Journal of Women's Health

\section{Publish your work in this journal}

The International Journal of Women's Health is an international, peerreviewed open-access journal publishing original research, reports, editorials, reviews and commentaries on all aspects of women's healthcare including gynecology, obstetrics, and breast cancer. The manuscript management system is completely online and includes

\section{Dovepress}

a very quick and fair peer-review system, which is all easy to use. Visit http://www.dovepress.com/testimonials.php to read real quotes from published authors. 